\title{
KARAKTER NAMA TOKOH WAYANG PADA PAPAN NAMA PENANDA GANG DI KOTA PROBOLINGGO: KAJIAN LANSKAP LINGUISTIK PENDEKATAN BUDAYA
}

\author{
THE WAYANG CHARACTER'S NAME IN THE GANG SIGNS \\ IN THE PROBOLINGGO CITY: A CULTURAL APPROACHES OF \\ LINGUISTIC LANDSCAPE STUDY
}

\author{
Khilmi Mauliddian ${ }^{1}$ Ika Nurhayani ${ }^{2}$, Hamamah $^{3}$ \\ Magister Ilmu Linguistik, Fakultas Ilmu Budaya, Universitas Brawijaya \\ 1'khilmi.mauliddian@gmail.com, ${ }^{2}$ inurhayani@ub.ac.id, ${ }^{3}$ hamamah@ub.ac.id
}

\begin{abstract}
ABSTRAK
Karakter nama wayang pada papan nama penanda gang di kota Probolinggo: kajian lanskap linguistik pendekatan budaya meneliti pada papan penanda gang yang memakai nama tokoh wayang sebagai penandanya. Tujuan penelitian ini adalah untuk mengetahui nama tokoh wayang dan mendeskripsikan karakter wayang yang ada pada papan penanda gang di kota Probolinggo. Penelitian ini menggunakan metode kualitatif dengan menggunakan dua pendekatan teori yaitu, lanskap Linguistik Landry dan Bourhis dan teori simbol budaya dari Bastomi. Adapun teknik pengumpulan data dalam penelitian ini menggunakan alat berupa kamera foto. Data yang dihimpun berupa foto yang berisi tulisan nama tokoh wayang pada papan penanda gang kemudian dikaitkan dengan aspek budaya yaitu karakter tokoh wayang. Hasil dari penelitian ini menunjukkan terdapat satu nama kelompok yaitu Pendawa, dan lima nama tokoh wayang yakni Nakula, Sadewa, Bima, Kresna, dan Srikandi. Terkait karakter yang dimiliki, kelima nama tokoh wayang memiliki karakter yang berbeda-beda namun semuanya merepresentasikan sisi kebaikan. Penelitian ini diharapkan dapat bermanfaat dalam menggali data bahasa dalam bingkai lanskap linguistik dengan pendekatan budaya.
\end{abstract}

Kata kunci: karakter, wayang, lanskap linguistik, budaya

\section{ABSTRACT}

This research examines the gang sign board that uses the name of a wayang character as a marker. The purpose of this study was to determine the name of the wayang character and describe the character of the wayang that is on the gang sign board in the Probolinggo city. This study uses a qualitative method using two theoretical approaches namely, Landry and Bourhis Linguistic landscape and the theory of cultural symbols from Bastomi. The data collection techniques in this study used a tool in the form of a photo camera. Data collected in the form of photos containing the writing of the name of the wayang character on the gang sign board and then associated with cultural aspects of the character wayang characters. The results of this study indicate there is one group name namely Pendawa, and five names of wayang figures namely Nakula, Sadewa, Bima, Kresna, and Srikandi. Related to the characters that are owned, the five names of wayang characters have different characters but all of them represent the good 
Tuah Talino

Tahun XIII Volume 13 Nomor 1 Edisi 5 Juli 2019

ISSN 0216-079X

Balai Bahasa Kalimantan Barat

side. This research is expected to be useful in exploring language data in a linguistic landscape frame with a cultural approach.

Keywords: characters, wayang, linguistic landscape, culture

\section{LATAR BELAKANG}

Studi lanskap linguistik dapat dikatakan sebagai bagian dari sosiolinguistik dan linguistik terapan yang berkaitan dengan "wujud tertulis" bahasa pada ruang umum (Gorter dan Cenoz 2006: 2) Bidang lanskap linguistik pada kajiannya menganalisis tanda-tanda baik komersial ataupun pemerintah, nama tempat, jalan, gang, lingkungan etnik atau budaya, dan kota-kota baik besar maupun kecil dan semakin berkembang ke ranah lainnya (Thontong, 2016). Maka dari itu tandatanda yang ada pada ruang publik dapat merefleksikan dan sekaligus mengatur tatanan ruang tempat ia beroperasi (Erikha, 2018:41).

Tanda-tanda dalam ruang publik juga secara tidak langsung menggambarkan aspek budaya maupun sosial serta aspek lain yang menentukan bagaimana tanda-tanda itu bekerja, sehingga tanda itu akan berperan terhadap penerima tanda. Menurut Blommaert (2013) tanda di ruang publik juga dapat memaksa audiensi agar mengikuti aturan mainnya, dengan sejumlah batasan dan pedoman norma yang dianut bersama. Tanda dalam ruang publik sebenarnya memiliki pesan dan tidak pernah netral, memiliki keterhubungan dengan struktur sosial, hierarki, dan kekuasaan (Stroud dan Mpendukana, 2009).

Salah satu kota yang menarik untuk dikaji penanda lanskap linguistiknya atau biasa disebut LL adalah kota Probolinggo. Kota ini merupakan salah satu kota yang ada di provinsi Jawa Timur bagian timur. Secara geografis kota ini terletak di pesisir pantai dengan selat Madura sebagai batas wilayah utara. Posisi Kota Probolinggo berdasarkan peta diapit oleh wilayah kabupaten Probolinggo dimana secara administratif merupakan pemerintahan kotamadya. Namun demikian dari kesamaan secara kultur bahasa dan budaya keduanya mempunyai kemiripan, yaitu sama-sama terasimilasi oleh dua budaya yaitu Jawa dan Madura.

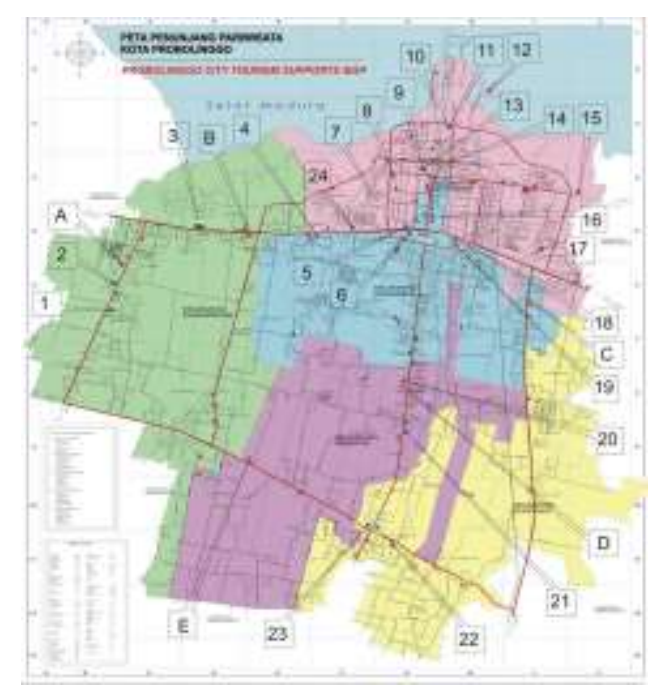

Gambar 1. Peta wilayah kota Probolinggo (Sumber: portal.probolinggokota.go.id) 
Sebagai wilayah kota, Probolinggo terbagi ke dalam beberapa wilayahwilayah administratif seperti di daerah lain pada umumnya. Wilayah tersebut meliputi kecamatan, kelurahan, RW, RT, gang, jalan dan disertai identitas tulisan suatu nama di dalamnya. Tujuannya agar semua orang mudah mengenali dan memahami wilayah yang ditempatinya. Inilah yang kemudian disebut sebagai salah bentuk penanda publik yakni penanda bahasa yang ada di ranah publik.

Bicara mengenai nama tempat di kota Probolinggo, kota ini mempunyai beragam nama tempat yang berbeda-beda. Adapun nama-nama tersebut tersebar dan hidup tertulis pada papan penanda publik. Salah satu yang menarik untuk di kaji adalah penanda publik yang di dalamnya tertulis nama wayang. Papan penanda publik ini berdiri dan hidup sebagai penanda pada gang atau jalan kecil di kota Probolinggo. Nama-nama wayang yang digunakan sebagai penanda publik di kota Probolinggo telah lama ada. Namun dalam kenyataannya penanda ini hanya sebatas sebagai penanda publik saja. Padahal dibalik papan penanda nama wayang, terdapat nilai cerita yang bisa digali. Hal ini selaras dengan pernyataan Erikha (lihat Erikha, 2018:41) bahwa nama jalan merupakan pesan berisi komunikasi antara pembuat pesan dan penerima.

Bicara mengenai nama tokoh wayang pada penanda publik maka tidak akan lepas mengenai kebudayaan Jawa yakni kesenian wayang kulit. Menurut G.A.J. Hazeu dalam Mertosedono (1994:28) mengatakan bahwa wayang dalam bahasa/kata Jawa berarti: bayangan, dalam bahasa melayu artinya: bayangbayang, yang artinya bayangan, samar-samar, menerawang. Wayang merupakan manifestasi dari gambaran sifat manusia dengan tingkah lakunya, berisi pesan moral serta mengenai hubungan antara manusia dengan Tuhan Sang Pencipta Alam Semesta, mengenai hubungan antara rakyat dengan penguasa, mengenai hubungan antara anak dengan orang tuanya (Pranoto, 2007:12). Selain itu wayang merupakan lambang kehidupan manusia di dunia (Hardjowigoro, 1989:11). Dalam cerita wayang terdapat tokoh nama-nama wayang dan tiap-tiap tokohnya merupakan refleksi atau representasi dari sikap, watak, dan karakter manusia secara umum (Aizid, 2012:12). Dengan demikian dapat disimpulkan bahwa pada setiap nama atau tokoh wayang mempunyai karakter tokoh yang dirangkai dengan jalan cerita sehingga memberikan pesan moral. Demikian pula maksud nama wayang yang ada pada penanda gang.

Berangkat dari latar belakang di atas maka peneliti mengambil bahan kajian penelitian dengan judul "Karakter Nama Tokoh Wayang Pada Papan Nama Penanda Gang di kota Probolinggo: Kajian Lanskap Linguistik Pendekatan Budaya". Adapun fokus penelitian adalah karakter nama tokoh wayang yang ada pada penanda gang di Kota Probolinggo. Alasan peneliti menggunakan objek papan nama pada penanda gang karena ingin mengetahui lebih dalam karakter nama wayang pada papan nama penanda publik menggunakan pendekatan LL dan dan kajian budaya. Pendekatan LL mengacu pada teori Landry dan Bourhis (1997:25) yaitu bahasa rambu-rambu pada jalan umum, iklan billboard, nama jalan, nama-nama tempat, tanda-tanda penunjuk pada toko komersial, dan tandatanda umum di gedung-gedung pemerintah menyatu dan membentuk lanskap linguistik dari suatu wilayah, wilayah aglomerasi atau pusat perekonomian, atau 
Tuah Talino

Tahun XIII Volume 13 Nomor 1 Edisi 5 Juli 2019

ISSN 0216-079X

Balai Bahasa Kalimantan Barat

perkotaan tertentu. Sedangkan pendekatan budaya menggunakan acuan teori simbol dari Bastomi yaitu, simbol atau lambang dalam budaya Jawa adalah suatu pedoman untuk berperilaku yang mempunyai fungsi sebagai petunjuk jalan yang memberikan arah terhadap pengalaman hidup yang dialami oleh manusia (Bastomi, 1993:55).

Penelitian terdahulu terkait karakter nama wayang pada papan penanda publik belum ada yang melakukan. Namun terdapat satu penelitian sebelumnya yang peneliti temukan dengan objek mengkaji papan nama dalam bingkai LL. Penelitian ini dilakukan oleh Erikha Fajar (2018). Hasil penelitiannya menunjukkan bahwa situasi LL di jalan-jalan utama kerajaan (râjamârga) di Kota Yogyakarta menunjukkan dua fungsinya: fungsi informasional dan fungsi simbolis. Oleh sebab itu, berdasarkan penelitian terdahulu, terdapat perbedaan yang diangkat dalam penelitian ini. Adapun perbedaannya terdapat pada cara pendekatan yang digunakan, yakni penelitian ini menggunakan pendekatan LL dan kajian kebudayaan wayang.

Dalam penelitian ini terdapat satu masalah pokok yang akan dibahas, yakni bagaimanakah karakter nama tokoh wayang yang ada pada papan nama penanda gang di kota Probolinggo? Sehubungan dengan rumusan masalah, yang menjadi tujuan penelitian ini adalah mengetahui nama tokoh wayang dan mendeskripsikan karakter wayang yang ada pada papan penanda jalan di kota Probolinggo.

\section{METODE}

Jenis penelitian ini adalah penelitian kualitatif. Metode kualitatif menekankan pada data yang diperoleh dalam bentuk kata, frasa, klausa, kalimat, wacana. Seperti yang dikemukakan Moleong (2010:27) bahwa penelitian kualitatif merupakan penelitian dengan maksud untuk memahami fenomena tentang apa yang dialami subjek penelitian secara menyeluruh dan dengan cara deskriptif dalam bentuk kata-kata dan bahasa, pada suatu konteks khusus yang alamiah dan dengan memanfaatkan berbagai metode ilmiah. Adapun desain penelitian ini adalah deskripstif kualitatif sehingga data yang dianalisis tidak berupa angka-angka, melainkan berupa kata-kata (Mahsun, 2005:27). Penelitian ini menghasilkan data yakni data berupa tulisan nama tokoh wayang dan deskripsi karakter nama wayang dengan menggunakan metode pendekatan teori LL dan Budaya. Untuk pengumpulan data penelitian ini menggunakan teknik pengambilan gambar dengan alat kamera foto. Kegiatan analisis data dalam penelitian ini meliputi identifikasi data, penyajian data, dan penarikan simpulan.

\section{PEMBAHASAN}

Menurut Uhlenbeck (1982:372) nama bagi orang Jawa bukan sekadar identitas diri namun juga berfungsi sebagai penanda status sosial yang menunjukkan derajat bagi orang yang mempunyai nama tersebut. Begitu juga nama yang ada pada penanda gang, dimaksudkan bahwa gang tersebut memiliki makna sesuai nama yang dipasang. Berdasarkan data LL pada papan nama penanda gang di kota Probolinggo, terdapat nama-nama tokoh wayang yang digunakan sebagai penanda publik. Berdasarkan hasil pengamatan, lokasi papan penanda ini terletak di kawasan Jl. Slamet Riyadi, Kelurahan Kanigaran, 
Tuah Talino

Tahun XIII Volume 13 Nomor 1 Edisi 5 Juli 2019

ISSN 0216-079X

Balai Bahasa Kalimantan Barat

kecamatan Kanigaran. Jumlah papan penanda gang yang menunjukkan atau menggunakan nama tokoh wayang sebanyak enam buah. Di bawah ini akan dijelaskan nama-nama tokoh wayang sekaligus disertai deskripsi singkat mengenai karakternya:

1. Gang Pendawa

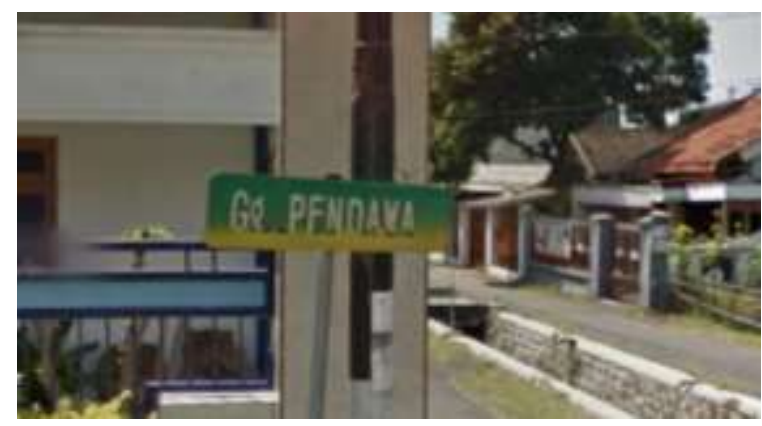

Gambar 2. Papan penanda bertuliskan nama Pendawa

Dalam dunia pewayangan, Pandawa adalah sebutan dari lima bersaudara putra dari Pandu Dewanata yakni, Yudistira, Bima, Arjuna, Nakula dan Sadewa. Persaudaraan sejumlah lima orang inilah mereka biasa disebut sebagai Pendawa Lima. Menurut Zoutmulder (1985:467) menjelaskan bahwa lima orang bersaudara ini merupakan keturunan dewa yang diutus untuk membunuh Kurawa jika sudah tiba waktunya. Lebih lanjut dijelaskan, pembunuhan ini sebagai akibat karena Kurawa selalu menebarkan kebencian, kesemena-menaan, dan rakus akan kekuasaan.

Berdasarkan nama, gang ini memiliki fungsi sebagai simbol yang memiliki makna bagi masyarakat sekitar. Selaras dengan cerita Pendawa, gang ini memiliki simbol yang berfungsi agar kehidupan masyarakat selalu menjunjung tinggi rasa persaudaraan satu sama lain, tanpa membeda-bedakan atau toleransi, sehingga tercipta rasa aman, tenteram, dan damai.

2. Gang Nakula

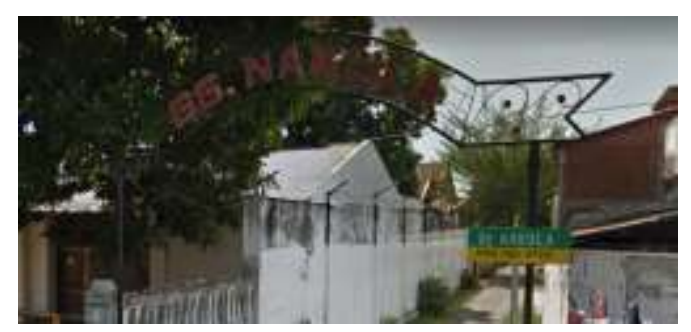

Gambar 3. Papan penanda bertuliskan nama tokoh wayang Nakula

Nakula merupakan nama salah satu tokoh Wayang kulit dalam kesenian tradisional masyarakat Jawa dan merupakan anggota dari Pendawa. Menurut cerita Nakula mempunyai saudara kembar yang bernama Sadewa. Nakula bisa dibilang jelmaan dari Dewa kembar bernama Aswin, yang sering dikenal sebagai dewa Pengobatan. Namun, orang tua Nakula dan Sadewa meninggal sehingga 
Tuah Talino

Tahun XIII Volume 13 Nomor 1 Edisi 5 Juli 2019

ISSN 0216-079X

Balai Bahasa Kalimantan Barat

mereka diasuh oleh Dewi Kunti, Istri Pandu yang lainnya. Nakula merupakan Kesatria yang ahli dalam bermain pedang. Nakula memiliki watak yang yaitu jujur, setia, taat dan patuh terhadap orang tuanya (www.jagad.id).

Berdasarkan nama, gang ini memiliki fungsi yang selaras dengan cerita Nakula. Adapun sesuai fungsinya gang ini memiliki simbol agar kehidupan masyarakat selalu mengedepankan sikap kesatria yang selalu menjunjung tinggi nilai-nilai kejujuran, kesetiaan, dan selalu taat patuh terhadap orang tuanya.

\section{Gang Sadewa}

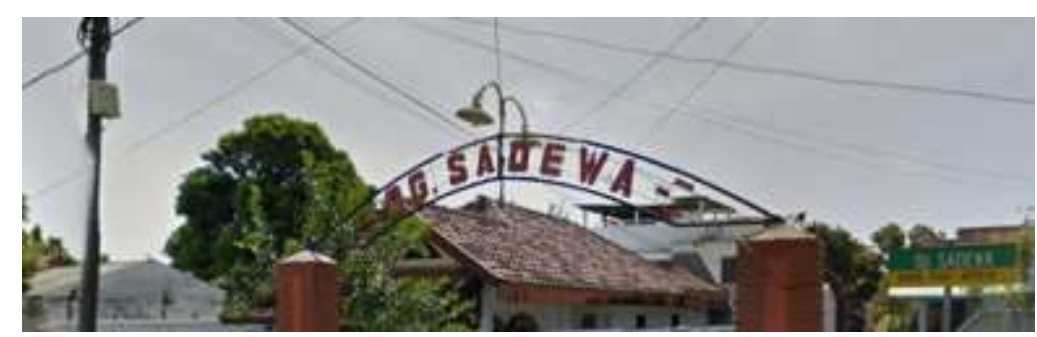

Gambar 4. Papan penanda bertuliskan nama tokoh wayang Sadewa

Karakter Sadewa merupakan saudara kembar dari Nakula yang juga merupakan anggota Pendawa. Sadewa juga merupakan putra kembar dari Prabu Pandu dan Dwi Mardim. Sama halnya dengan Nakula, saat kecil Sadewa diasuh oleh Dewi Kunti, Istri Pandu yang lainnya. Sadewa ahli dalam ilmu Astronomi. Sadewa memiliki watak yang sama dengan Nakula yaitu jujur, setia, taat dan patuh terhadap orang tuanya (www.jagad.id).

Berdasarkan nama, gang ini memiliki fungsi yang selaras dengan cerita Sadewa. Adapun sesuai fungsinya gang ini memiliki simbol yang sama dengan nama Nakula yakni agar kehidupan masyarakat selalu mengedepankan sikap kesatria yang selalu menjunjung tinggi nilai-nilai kejujuran, kesetiaan, dan selalu taat patuh terhadap orang tuanya.

\section{Gang Bima}

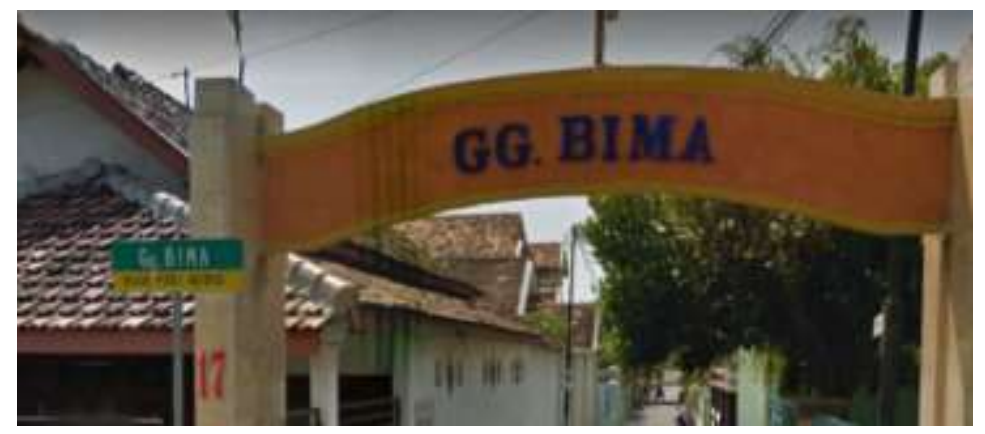

Gambar 5. Papan penanda bertuliskan nama tokoh wayang Bima

Bima merupakan nama kecil dari Werkudara anak dari perkawinan Prabu Pandu dan Dewi Kunti. Nama Bima dalam bahasa sansekerta memiliki arti yakni mengerikan. Bima merupakan saudara dari Nakula dan Sadewa. Dia merupakan 
seorang Pandawa yang kuat, memiliki lengan yang panjang, tubuh yang tinggi dan memiliki wajah paling gagah dan sangar dibanding 4 pandawa lainnya. Walaupun terbilang menyeramkan ditambah membawa senjata bernama Gada, namun ia memiliki hati yang baik tidak seperti kelihatannya. Bima memiliki sifat dan perwatakan; gagah berani, teguh, kuat, tabah, patuh dan jujur. Bima juga sangat dibutuhkan terutama kemahirannya dalam berperang agar mereka bisa memenangkan peperangan dalam pertempuran akbar di Khurukseta. Perlu anda ketahui, Gatot Kaca merupakan anak dari Werkudara dari Ras Rakhsasa. selain Gatotkaca, Bima juga memiliki 2 anak lainnya bernama Antareja dan Antasena dalam pewayangan Jawa (https://tokohpewayanganjawa.blogspot.com).

Berdasarkan nama, gang ini memiliki fungsi yang selaras dengan cerita Bima. Adapun sesuai fungsinya gang ini memiliki simbol yakni agar kehidupan masyarakat mencerminkan perilaku seperti Bima yakni memiliki sifat dan perwatakan; gagah berani, teguh, kuat, tabah, patuh dan jujur dalam menjalani kehidupan.

\section{Gang Kresna}

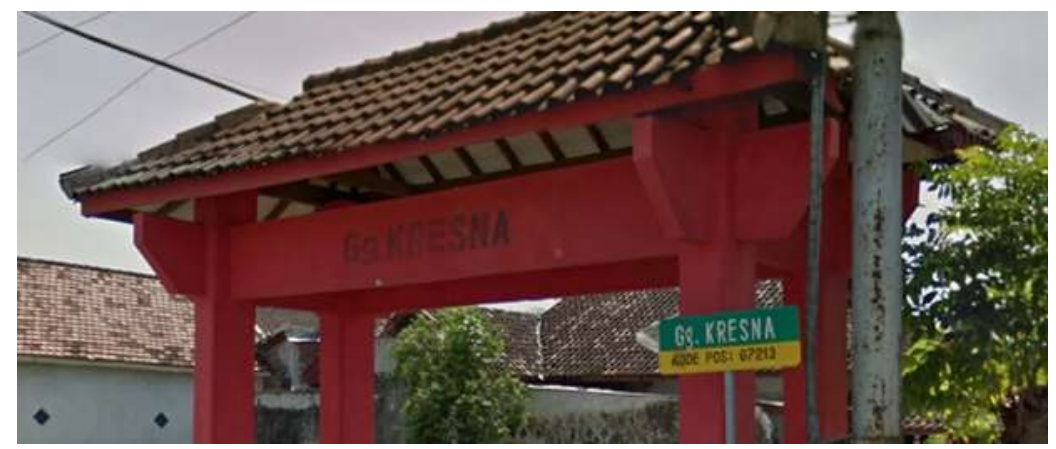

Gambar 6. Papan penanda bertuliskan nama tokoh wayang Kresna

Karakter Kresna dapat dilihat dari berbagai cerita riwayat hidup dan sikap hidupnya. Dalam cerita masa kanak-kanaknya, Kresna adalah anak luar biasa keberanian dan kesaktiannya. Pada masa remaja dan dewasa Kresna sebagai remaja yang gemar bertapa, berkemauan keras dan pemberani. Sebagai anggota keluarga, Kresna suka menolong saudara-saudara yang dalam kesusahan dan membutuhkan pertolongan. Selama berkedudukan sebagai raja Dwarawati, Kresna sebagai raja yang telah memahami dan mengamalkan makna yang terkandung dalam asthabrata. Artinya ia memiliki sifat delapan dewa yang mencerminkan kelebihan dan kehebatan para pemimpin atau pelindung dunia. Kresna berjiwa jujur, membela kebenaran dan keadilan. Sikap Kresna mencerminkan sifat-sifat ambek paramarta, ambek pinandhita dan ambek binathara (www.wayang.wordpress.com).

Berdasarkan nama, gang ini memiliki fungsi yang selaras dengan cerita Kresna. Sesuai fungsinya, gang ini memiliki simbol yakni agar kehidupan masyarakat berperilaku dan berwatak seperti Kresna. Perilaku masyarakat yang diharapkan yaitu dapat mengedepankan sikap suka menolong sesama dan menanamkan jiwa jujur, membela kebenaran dan keadilan. 
Tuah Talino

Tahun XIII Volume 13 Nomor 1 Edisi 5 Juli 2019

ISSN 0216-079X

Balai Bahasa Kalimantan Barat

6. Gang Srikandi

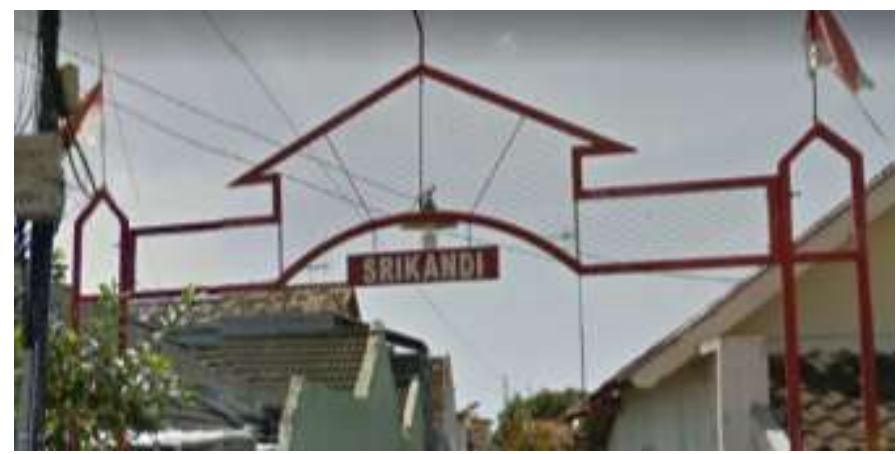

Gambar 7. Papan penanda bertuliskan nama tokoh wayang Srikandi

Dewi Wara Srikandi merupakan istri dari Arjuna dan seorang tokoh wayang yang memiliki karakter pemberani, bersuara nyaring, keras, dan handal atau piawai dalam olah panah (http://nuradiwibowo02.blogspot.com). Yang menjadi watak dominan dalam diri Srikandi yaitu ia bersemangat, pemberani, memiliki tekad yang kuat, dan percaya diri. Terkadang, karena rasa tahu yang besar Srikandi suka bertindak sepontan saja. Srikandi juga menjadi salah satu wanita yang memukau terutama saat ia memperjuangkan kebenaran (Miranti, Azmy, 2018:21). Selain itu Srikandi merupakan seorang wanita yang memiliki tabiat seperti laki-laki, ia juga suka dengan olah panah, berperang, berkuda, dan yang lainnya. Hal ini bukan semata-mata ia lakukan untuk kesenangan melainkan bertujuan agar mampu menjaga dirinya sendiri juga menjaga orang lain dari tindak kejahatan. Solichin (2018) menyebutkan, bahwa Srikandi adalah seorang putri raja Cempala yang mencapai kedudukannya dan ketenarannya bukan karena ia adalah anak seorang raja, tetapi karena Srikandi sedari remaja sudah berjuang untuk mendapatkan itu semua.

Berdasarkan nama, gang ini memiliki fungsi yang selaras dengan semangat cerita Srikandi. Sesuai fungsinya, gang ini memiliki simbol yakni agar kehidupan masyarakat berperilaku dan berwatak seperti Srikandi. Watak tersebut ntara lain yaitu, selalu bersemangat, pemberani, memiliki tekad yang kuat, dan percaya diri. Selain itu, agar masyarakat dalam kehidupannya selalu memperjuangkan kebenaran.

Untuk mendapatkan gambaran lebih jelas terkait data nama tokoh wayang dan deskripsi karakternya sesuai dengan analisis di atas, berikut dapat dilihat pada tabel di bawah ini: 
Tahun XIII Volume 13 Nomor 1 Edisi 5 Juli 2019

ISSN 0216-079X

Balai Bahasa Kalimantan Barat

Tabel 1. Data Nama Tokoh Wayang dan Karakter

\begin{tabular}{|c|c|c|c|}
\hline $\begin{array}{c}\text { No } \\
\text { Data }\end{array}$ & $\begin{array}{l}\text { Tulisan Nama } \\
\text { Tokoh Wayang } \\
\text { pada Papan } \\
\text { Penanda Gang }\end{array}$ & Karakter & Keterangan \\
\hline 1. & Pendawa & & $\begin{array}{l}\text { sebutan dari lima } \\
\text { bersaudara putra dari Pandu } \\
\text { Dewanata yakni,Yudistira, } \\
\text { Bima, Arjuna, Nakula dan } \\
\text { Sadewa }\end{array}$ \\
\hline 2. & Nakula & $\begin{array}{l}\text { Nakula merupakan Kesatria yang ahli dalam } \\
\text { bermain pedang. Nakula memiliki watak } \\
\text { yaitu jujur, setia, taat dan patuh terhadap } \\
\text { orang tuanya }\end{array}$ & $\begin{array}{l}\text { Merupakan bagian dari } \\
\text { anggota Pendawa }\end{array}$ \\
\hline 3. & Sadewa & $\begin{array}{l}\text { Sadewa ahli dalam ilmu Astronomi. Sadewa } \\
\text { memiliki watak yang sama dengan Nakula } \\
\text { yaitu jujur, setia, taat dan patuh terhadap } \\
\text { orang tuanya }\end{array}$ & $\begin{array}{l}\text { Merupakan bagian dari } \\
\text { anggota Pendawa }\end{array}$ \\
\hline 4. & Bima & $\begin{array}{l}\text { Bima merupakan nama kecil dari } \\
\text { Werkudara. Bima memiliki sifat dan } \\
\text { perwatakan; gagah berani, teguh, kuat, } \\
\text { tabah, patuh dan jujur }\end{array}$ & $\begin{array}{l}\text { Merupakan bagian dari } \\
\text { anggota Pendawa }\end{array}$ \\
\hline 5. & Kresna & $\begin{array}{l}\text { Karakter Kresna berdasarkan dengan } \\
\text { perkembangan masa usia dan perannya, } \\
\text { antara lain: } \\
\text { 1. Masa kecil, Kresna adalah anak luar } \\
\text { biasa keberanian dan kesaktiannya. } \\
\text { 2. Pada masa remaja dan dewasa, Kresna } \\
\text { gemar bertapa, berkemauan keras dan } \\
\text { pemberani. } \\
\text { 3. Sebagai anggota keluarga, Kresna suka } \\
\text { menolong saudara-saudara yang dalam } \\
\text { kesusahan dan membutuhkan } \\
\text { pertolongan. } \\
\text { 4. sebagai raja, Kresna berjiwa jujur, } \\
\text { membela kebenaran dan keadilan. }\end{array}$ & $\begin{array}{l}\text { Raja pada } \\
\text { Dwarawati }\end{array}$ \\
\hline 6. & Srikandi & $\begin{array}{l}\text { Pemberani, bersuara nyaring, keras, dan } \\
\text { handal atau piawai dalam olah panah. Watak } \\
\text { dominan dalam diri Srikandi yaitu ia } \\
\text { bersemangat, pemberani, memiliki tekad } \\
\text { yang kuat, dan percaya diri. Terkadang, } \\
\text { karena rasa tahu yang besar Srikandi suka } \\
\text { bertindak sepontan saja. }\end{array}$ & Istri dari Arjuna \\
\hline
\end{tabular}

Dengan demikian, nama tokoh wayang yang terdapat pada papan nama penanda gang di kota Probolinggo ternyata memiliki karakter pada setiap nama yang melekat. Meskipun papan nama penanda merupakan salah satu bingkai dari LL, namun dengan konsep LL tulisan pada papan penanda tersebut dapat digali secara mendalam sehingga banyak informasi yang didapat. Dengan menggunakan 
pendekatan dua sisi, yakni aspek LL dan budaya, maka proses penggalian informasi dapat berjalan secara efektif.

\section{SIMPULAN}

Berdasarkan hasil penelitian di atas dapat diperoleh simpulan yaitu terdapat enam wujud nama tokoh wayang pada papan nama gang di kota Probolinggo. Keenam nama tokoh wayang tersebut terdiri dari satu nama jenis kelompok yakni Pandawa, dan lima nama tokoh wayang antara lain, Nakula, Sadewa, Bima, Kresna, dan Srikandi. Nama Pandawa merupakan nama kelompok yang merujuk pada satu-kesatuan yang terdiri dari lima orang saudara. Sedangkan ke lima nama tokoh yang lain merupakan representasi dari masing-masing individu pada setiap nama wayang. Maka setiap individu dari lima nama tokoh wayang tersebut memiliki karakter yang berbeda-beda. Dari karakter yang dimiliki oleh ke lima nama tokoh wayang tersebut ditemukan satu benang merah fakta bahwa semua karakter dari masing-masing nama tokoh wayang merupakan representasi dari sisi karakter yang baik. Representasi ini sekaligus merupakan bagian dari sisi kehidupan yang ada dalam dunia manusia. Dengan demikian dapat dikatakan bahwa penelitian kajian LL dengan pendekatan budaya telah mampu menggali aspek lain dari bahasa yang dalam papan nama pada penanda publik, salah satunya nama-nama wayang dalam penanda gang di kota Probolinggo.

\section{SARAN}

Penelitian ini merupakan penelitian dengan konsep dua pendekatan bidang kajian yaitu, LL dan budaya, sehingga pendekatan dengan menggunakan kedua teori perlu dikaji secara komprehensif. Sebab, sejauh peneliti ketahui belum ada yang menggunakan model pendekatan ini. Selain itu penelitian ini dapat digunakan sebagai ancangan penelitian-penelitian selanjutnya yang memanfaatkan kombinasi atau gabungan dari kedua teori tersebut. Oleh sebab itu peneliti menyadari bahwa penelitian ini masih sangat terbatas sehingga perlu dilakukan penelitian-penelitian lanjutan yang lebih mendalam dengan menggunakan model pendekatan kedua teori.

\section{DAFTAR PUSTAKA}

Aizid, Rizem. (2012). Atlas Tokoh-Tokoh Wayang. Yogyakarta: Diva Press.

Blommaert, Jan. (2013). Ethnography, Superdiversity and Linguistic Landscapes: Chronicles of Complexity. Ontario: Multilingual Matters.

Bastomi, Suwaji. (1993). Seni dan Budaya Jawa. Semarang. IKIP Semarang Press.

Erikha, Fajar. (2018). Konsep Lanskap Linguistik pada Papan Nama Jalan Kerajaan (Rajamarga): Studi Kasus Kota Yogyakarta. Paradigma, 8 (1), 3852.

Gorter, D. (Ed.). (2006). Linguistic landscape: A new approach to multilingualism. Multilingual Matters.

Hardjowirogo. (1989). Sedjarah Wayang Purwa. Jakarta: Balai Pustaka 
Landry, Rodrigue, dan Richard Y. Bourhis. (1997). Linguistic Landscape and Ethnolinguistic Vitality: An Empirical Study. Journal of Language and Social Psychology 16, no. 1: 23-49.

Mahsun, M.S. (2005). Metode Penelitian Bahasa Tahapan Strategi, Metode, dan Tekniknya. Jakarta: Raja Grasindo Persada

Mertosedono, Amir. (1994). Sejarah Wayang, Asal-Usul, Jenis dan Cirinya. Semarang: Dahara.

Miranty, Delatari dan Amzy, Nurulfatmi. 2018. Analisis Karakter Tokoh Wayang Srikandi dalam Lakon Perang Bahratayuda sebagai Pembelajaran Karakter untuk Remaja. Jurnal Kreasi Seni dan Budaya, 01 (01), 20-24.

Moleong, Lexy J. (2010). Metodologi penelitian kualitatif. Bandung: Rosda Karya

Pranoto,Teguh. (2007). Ajaran Hidup Tuntunan Luhur Piwulang Agung. Solo: Kuntul Press.

Solichin. (2018). Tokoh Wayang Terkemuka. Yayasan Senawangi. Jakarta: CV. Dedy Jaya.

Stroud, C., dan S. Mpendukana. (2009). Towards a Material ethnography of Linguistic Landscape: Multilingualism, Mobility and Space in a SouthAfrican Township. Journal of Sociolinguistics 13, no. 3: 363-383.

Thongtong, Tiwahporn. (2016). A Linguistic Landscape Study of Signage on Nimmanhemin Road, A Lanna Chiang Mai Chill-Out Street. Manusya, 22, $72-87$.

Uhlenbeck, E.M. (1982). Kajian Morfologi Bahasa Jawa. Jakarta. Djambatan.

Zoetmulder. (1985). Kalangwan. Jakarta: Djambatan.

Website;

portal.probolinggokota.go.id diakses pada 11 Mei 2019

www.wayang.wordpress.com diakses pada 11 Mei 2019.

www.jagad.id diakses pada 11 Mei 2019.

http://nuradiwibowo02.blogspot.com diakses pada 11 Mei 2019.

https://tokohpewayanganjawa.blogspot.com) diakses pada 11 Mei 2019. 